\title{
Electrical Conductivities of Rock-Forming Minerals at High Temperatures
}

\author{
By \\ Hitoshi Mizutani and Hiroo Kanamori ${ }^{1)}$ \\ Geophysical Institute, The University of Tolkyo, Tolcyo
}

\begin{abstract}
Electrical conductivities of olivine, quartz, garnet, corundum, jadeite and alkali feldspar are measured over the temperature range 500 to $1200^{\circ} \mathrm{K}$. Electrical conductivities $\sigma$ of these rock-forming minerals can be expressed by an equation similar to that for semi-conductors;

$$
\sigma=\sigma_{01} \exp \left(-\epsilon_{1} / k T\right)+i_{02} \exp \left(-\varsigma_{2} / k T\right)+\cdots
$$

where $c_{i}$ 's are the activation energies, $k$, Boltzmann constant and $\sigma_{0 i}$ 's, constants. Although the type of conduction mechanism cannot be determined definitely, the activation energies of various rock-forming minerals fall between 0.7 and $1.7 \mathrm{eV}$ over the temperature range studied. The pre-exponential term $\sigma_{0 i}$, however, varies several orders of magnitude for different minerals.
\end{abstract}

\section{\$1. Introduction}

Electrical conductivity is an important parameter for estimating the temperature distribution in the earth's interior (Rikitake, 1952; Tozer, 1959). Several authors studied the temperature and pressure dependence of the electrical conductivity of rocks and minerals (Coster, 1948; Hughes, 1955; Noritomi, 1955, 1956, 1961; Bradley, Jamil and Munro, 1964; Akimoto and Fujisawa, 1965; Hamilton, 1965) but the electrical conductivity in the mantle is as yet poorly understood because of the paucity of the experimental clata.

The purpose of this paper is to determine the electrical conductivity of various rock. forming minerals over the temperature range 500 to $1200^{\circ} \mathrm{K}$ at normal pressures.

\section{\$2. Method}

The sample was cut in the shape of a cylincler, 2 to $3 \mathrm{~mm}$ long and about $10 \mathrm{~mm}^{2}$ in cross section. Both encls of the cylinder were coated with conductive coating material (DuPont no. 4731) to which lead wires were

1) Now at Earthquake Research Institute, The University of Tokyo, Tokyo. attached. The measurements were made in argon gas to avoid the oxidation of the sample. The reversibility of the measurements was good enough to ensure that no serious alteration occurred in the sample in the course of measurements.

A commercial vacuum tube voltmeter (TOA Electronics PM 20) was used to measure the resistance across the sample from which specific resistivities were calculated. The voltage applied to the sample was about 1.5 volts. To eliminate the effect of polarization by electrolysis, the polarity of electrodes was reversed automatically every $0.1 \mathrm{sec}$. The sample holder and its assemblage are shown in Fig. 1. They are so designed as to ensure

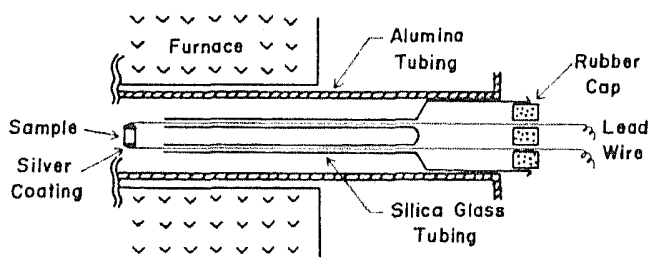

Fig. 1. The sample holder and its assemblage.

a complete insulation of the sample from the surroundings. Therefore absolute values of the conductivities are reliable. 
Table I. Names and brief description of the samples studied.

\begin{tabular}{ll|l}
\hline \multicolumn{1}{c|}{ Material } & \multicolumn{1}{c}{ Locality } \\
\hline Quartz [001] & & Minas Gerais, Brazil \\
Quartz [010] & & Minas Gerais, Brazil \\
Olivine [001] & 82\% Forsterite 18\% Fayalite & Miyake-jima, Japan \\
Jadeite & Polycrystal & Burma \\
Garnet-1 & 60\% Pyrope 40\% Almandite & Green's Creek, Delaware Penn. \\
Garnet-2 & 50\% Pyrope 50\% Almandite & Adirondack, N. Y. \\
Corundum & & Mogok, Burma \\
Alkali Feldspar & 61\% Orthoclase 34\% Albite 5\% Anorthite & Korea \\
\hline
\end{tabular}

\section{§ 3. Samples}

Names and brief descriptions of the samples are listed in Table I. Except jadeite, all the samples are single crystals of gem quality.

Table II. The results of chemical analyses of olivine and jadeite.

\begin{tabular}{l|c|c}
\hline & $\begin{array}{c}\text { Olivine } \\
\text { Miyake-jima, Japan }\end{array}$ & $\begin{array}{c}\text { Jadeite } \\
\text { Burma }\end{array}$ \\
\hline $\mathrm{SiO}_{2}$ & $38.82 \%$ & $57.86 \%$ \\
$\mathrm{Al}_{2} \mathrm{O}_{3}$ & 0.20 & 23.90 \\
$\mathrm{Fe}_{2} \mathrm{O}_{3}$ & 1.65 & 0.75 \\
$\mathrm{FeO}$ & 14.93 & \\
$\mathrm{MgO}$ & 42.51 & 1.23 \\
$\mathrm{CaO}$ & 0.40 & 1.24 \\
$\mathrm{Na} \mathrm{O}_{2} \mathrm{O}$ & & 13.85 \\
$\mathrm{~K}_{2} \mathrm{O}$ & & 0.11 \\
$\mathrm{MnO}$ & 0.23 & \\
\hline
\end{tabular}

The chemical composition of the jadeite is given in Table II. The olivine studied here is presumably similar in composition to that analyzed by Seto (1929). Seto's result is reproduced in Table II. Thermal diffusivities had been measured for these samples over the temperature range 300 to $1100^{\circ} \mathrm{K}$ (Kanamori, Fujii and Mizutani, 1968).

\section{§4. Results}

The logarithm of the measured specific resistivity is plotted against the reciprocal of the absolute temperature in Figs. 2, 3, 5, 6, and 7 , for olivine, quartz, garnet, corundum, alkali-feldspar and jadeite. All the measurements through three or four runs are plotted together. These figures show that the logarithm of specific resistivity varies linearly with the reciprocal of the absolute temperature. Therefore electrical conductivity $\sigma$ can be expressed by an equation similar to that for semi-conductors;

$$
\sigma=\sigma_{01} \exp \left(-\epsilon_{1} / k T\right)+\sigma_{02} \exp \left(-\epsilon_{2} / k T\right)+\cdots
$$

where $\epsilon_{i}$ 's are the activation energies, $k$, Boltzmann constant and $\sigma_{0 i}$ 's, constants. Smooth curves are fitted to the raw data; from these curves the values of $\sigma_{0 i}$ and $\epsilon_{i}$ are calculated and listed in Table III.

Table III. The values of activation energies $\epsilon_{i}$ and pre-exponential term $\sigma_{0 i}$ calculated from Figs. 2, 3, 5, 6, and 7 .

\begin{tabular}{l|c|c|c|c}
\hline \multicolumn{1}{c|}{ Material } & $\epsilon_{1}(\mathrm{eV})$ & $\sigma_{01}\left(\Omega^{-1} \mathrm{~cm}^{-1}\right)$ & $\epsilon_{2}(\mathrm{eV})$ & $\sigma_{02}\left(\Omega^{-1} \mathrm{~cm}^{-1}\right)$ \\
\hline Olivine [001] & 0.86 & 0.29 & & \\
Quartz [010] & 0.81 & 0.63 & & \\
Quartz [001] & 0.86 & 0.58 & & \\
Garnet-1 & 1.12 & 1.15 & & \\
Garnet-2 & 0.32 & $6.3 \times 10^{-5}$ & 1.2 & $2.8 \times 10$ \\
Corundum & 1.55 & $2.5 \times 10^{4}$ & 0.72 & 1.59 \\
Jadeite & 1.10 & $1.0 \times 10^{2}$ & 0.74 & 1.26 \\
Alkali & 1.65 & $8.0 \times 10^{8}$ & & \\
Feldspar & & & \\
\hline
\end{tabular}

\section{§5. Discussions}

The physical meaning of the activation energy $\epsilon_{i}$ depends on the type of conduction mechanism. For the extrinsic conduction, $\epsilon_{i}$ obtained from a portion of the $\log r-1 / T$ curve cannot be given a definite physical meaning. It may be either the energy required to excite an electron from an impurity level into the conduction band or a half of that. In case of the intrinsic conduction, the activation energy $\epsilon_{i}$ is half the energy gap between 
the valence band and the conduction band. In the ionic conduction, the activation energy is interpreted as the energy required to produce mobile ions. This energy is equal to the sum of the energy necessary for creating a pair of defects and that required for the ions to move from one site to another.

For quantitative discussions of the electrical conductivity in the mantle, it is essential to know what type of conduction mechanism is dominant over a given temperature and pressure range. In what follows we will discuss the type of conduction mechanism over the temperature range covered in the present study.

\section{Olivine (Fig. 2)}

Measurements were made in a direction parallel to the c-axis ([001] direction). Fig. 2 shows the present result as compared with those by other workers.

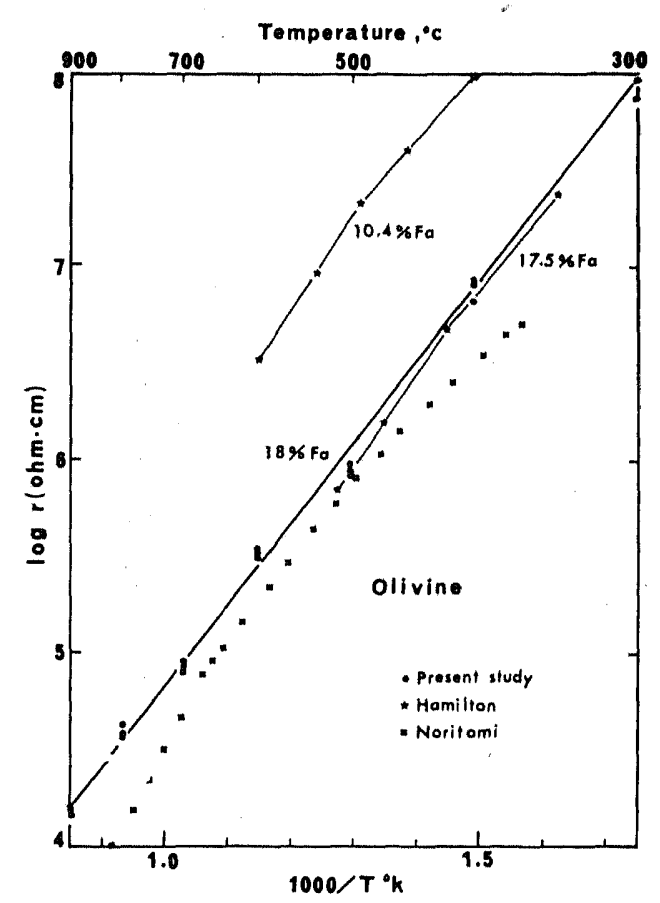

Fig. 2. Electrical conductivity of olivine in the direction parallel to the c-axis.

The present result for an olivine with $18 \%$ fayalite is in !good accord with that for a Bonin Island olivine with about 20\% fayalite studied by Noritomi (1961) and a powdered olivine with $17.5 \%$ fayalite studied by Hamilton (1965). The remarkable coincidence shown in Fig. 2 substantiates the argument of Hamilton who states that the pre-exponential term $\sigma_{0}$ and the activation energy $\epsilon$ are mainly governed by the fayalite content. Bradley et al. (1964) suggested that the "hopping mechanism" of electrons

$$
\mathrm{Fe}^{8+}+\mathrm{e} \rightleftarrows \mathrm{Fe}^{2+}
$$

is responsible for the conductivity of fayalite. If the ferric ion $\mathrm{Fe}^{8+}$ content is proportional to the fayalite content this mechanism gives a reasonable explanation for the strong dependence of the conductivity on the fayalite content. The ferric ion content, however, is controlled by the degree of oxidation rather than by the fayalite content. Actually pure fayalites do not contain a constant quantity of ferric ion. Thus the mechanism pointed out by Bradley et al. may not be suitable as the conduction mechanism of the olivine.

The olivines studied by various authors must contain different impurities in different amounts. If the impurity conduction is the major mechanism, the conductivities of the olivines cannot be so consistently explained in terms of the fayalite content alone as shown in Fig. 2. Therefore, the impurity conduction is also unlikely to be operative in the olivine. Thus it is suggested that the mechanism of electrical conduction in olivine over the temperature range $300^{\circ}$ to $1200^{\circ} \mathrm{K}$ is either the intrinsic or ionic conduction. Recently Shankland (1966) made an extensive study of the absorption spectrum of olivines. He found that the absorption in the range 3.3 to $7.5 \mathrm{eV}$ is not due to the intrinsic band gap of the lattice but due to $\mathrm{Fe}^{8+}$ ion. From the optical property of the olivines and the electrical concluctivity measured for synthetic forsterites, he considered the mechanism of electrical conduction in forsterite over the temperature range $300^{\circ}$ to $1200^{\circ} \mathrm{K}$ as ionic. The conduction mechanism of natural olivines may also be attributed to ionic conduction.

Quartz (Fig. 3)

Conductivities are measured in two direc- 
tions: perpendicular and parallel to the c-axis. The specific resistivity in the [001] direction is twice as large as that in the [010] direction, whereas the activation energies are the same for the two directions. In Fig. 4 are also

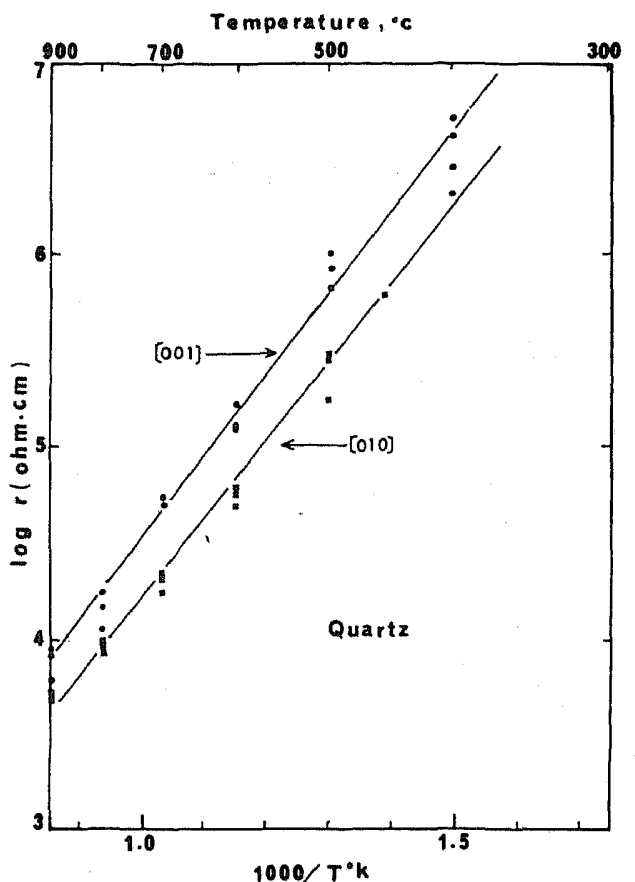

Fig. 3. Electrical conductivities of quartz in the [001] and [010] directions.

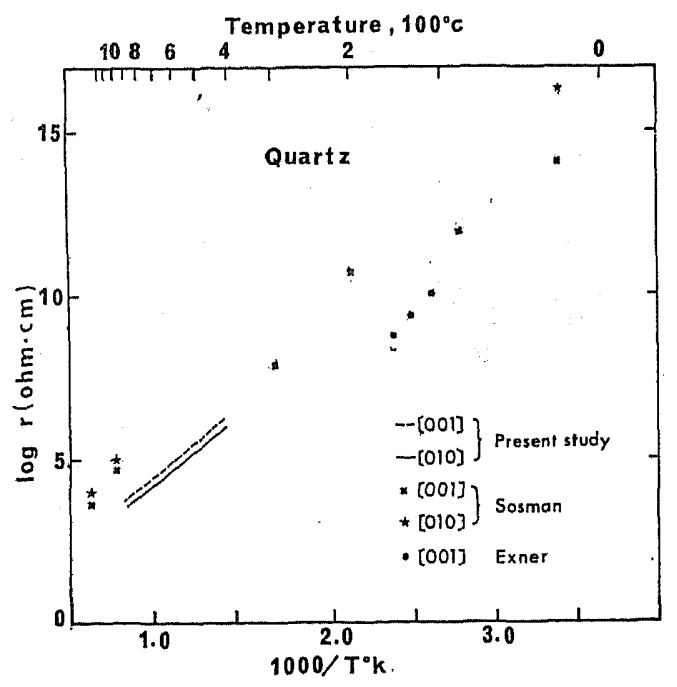

Fig. 4. Electrical conductivities of quartz by various authors. shown the data of Sosman (1927) and Exner (1901) for comparison. Sosman estimated the most probable values from the data of Thornton, Shaposhnikov, Curtis, Richardson, Saegusa, Curie, Tegetmeier and Warburg, Exner, Ambrann and Doelter. According to Sosman's estimate, contrary to our results, the specific resistivity in the [010] direction is larger than that in the [001] direction. Sosman's data cannot be fitted by a smooth curve but the overall trend is similar to that of the present result. Noritomi's (1955) data showed too complicated a variation with temperature, especially at low temperatures, to be included in Fig. 4. Noritomi reported that the specific resistivity in the [001] direction is larger than that in the [010] direction. In any case the difference of the conductivities in the two directions is not very large and the impurity may affect the ratio $\sigma[001] / \sigma[010]$.

The activation energy obtained from Fig. 3 is $0.78 \mathrm{eV}$ as listed in Table III. If the electrical conductivity observed over the temperature range 300 to $900^{\circ} \mathrm{K}$ is intrinsic, the energy gap will be $1.56 \mathrm{eV}$. The energy of absorption edge of quartz is found to be $6.2 \mathrm{eV}$ (McCarthy et al., 1963). This energy is much larger than the energy gap. Therefore it may be concluded that the type of electrical conduction over the temperature range 300 to $900^{\circ} \mathrm{K}$ is not intrinsic but extrinsic.

\section{Garnet (Fig. 5)}

Activation energies of Garnet-1 and Garnet-2 are approximately the same over the temperature range 550 to $900^{\circ} \mathrm{K}$, although their chemical compositions are different. This implies that the electronic structure is not sensitive to the chemical composition as ascertained by the optical studies on almandite and pyrope (Clark, 1957). For Garnet-2 the $\log r-1 / T$ curve has an inflection at about $T=550^{\circ} \mathrm{K}$. The conductivity at temperatures below and above the inflection may be due to the impurity and intrinsic conduction respectively. Since Garnet-2 contains a greater number of $\mathrm{Fe}^{++}$ion than Garnet-1 (see Table I), Garnet-2 may have a greater number of 


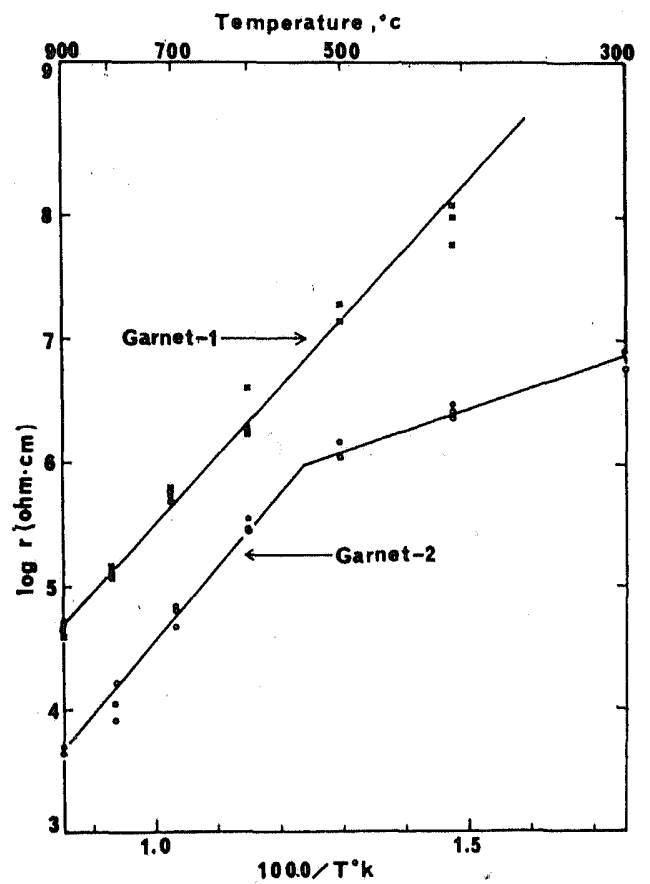

Fig. 5. Electrical conductivities of Garnet-1 and Garnet-2. Garnet-2 contains a greater number of $\mathrm{Fe}^{++}$ion than Garnet-1.

electrons trapped in the field of $\mathrm{Fe}^{++}$ions in the interstitial positions. This may be the reason why the $\log r-1 / T$ curve of Garnet-2 shows the inflection and $\sigma_{0 i}$ of Garnet-2 has a higher value than that of Garnet-1.

\section{Corundum (Fig. 6)}

Conductivity of the corundum has an inflection in the $\log r-T$ curve. Such an inflection was observed for Garnet-2 also (Fig. 5). As shown in Table III the activation energy above the critical temperature $T_{0}=650^{\circ} \mathrm{C}$ is equal to one half of that below the critical temperature. Temperature dependence of this type is typical of a semi-conductor with impurity centers larger in number than electrons (Mott and Gurney, 1948). According to the theory of extrinsic conduction, the ratio of $\sigma_{01}$ to $\sigma_{02}$ and the critical temperature $T_{0}$ at which two straight lines intersect in Fig. 6, are given by: (Mott and Gurney, 1948; pp. 159-160)

$$
\frac{\sigma_{01}}{\sigma_{02}}=\frac{\sqrt{\mathrm{NeV}}}{\mathrm{N}-\mathrm{Ne}}\left(\frac{2 \pi m k T}{h^{2}}\right)^{8 / 4}
$$

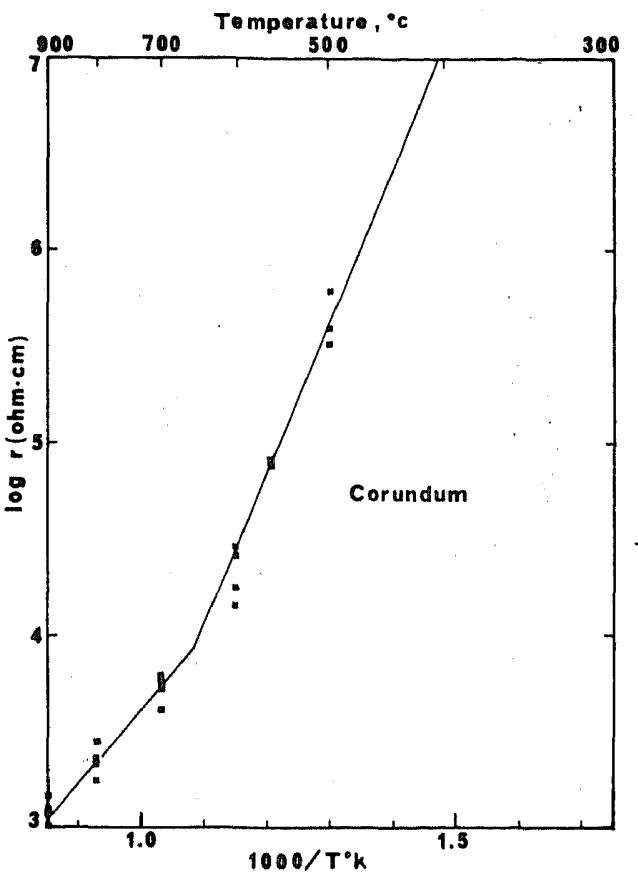

Fig. 6. Electrical conductivity of corundum.

$$
\frac{2(\mathrm{~N}-\mathrm{Ne})^{2}}{\mathrm{~V}(2 \mathrm{Ne}-\mathrm{N})}=\left\{\frac{2 \pi m k T_{0}}{h^{2}}\right\}^{8 / 2} \exp \left(-\epsilon_{1} / k T_{c}\right)
$$

where

$\mathrm{V}$; volume

$\mathrm{N}$; the number of impurity levels in $\mathrm{V}$

$\mathrm{Ne}$; the number of electrons available in $\mathrm{V}$

$m$; the mass of an electron

$k$; Boltzmann constant

$h$; Planck's constant

The values of $\sigma_{01} / \sigma_{02}, \epsilon_{1}$ and $T_{0}$ are $10^{4}, 1.55 \mathrm{eV}$ and $900^{\circ} \mathrm{K}$ respectively from Table $\mathrm{I}$ and Fig. 6. With these values the equations (1) and (2) can be satisfied at $T \sim 500^{\circ} \mathrm{K}$, if $\mathrm{N}$ and $\mathrm{Ne}$ are of the order of $10^{12} \mathrm{~cm}^{-3}$ and $\mathrm{N}-\mathrm{Ne} \sim 10^{11} \mathrm{~cm}^{-3}$. These values of $\mathrm{N}$ and $\mathrm{Ne}$ are reasonable (Kittel, 1956).

\section{Feldspar, Jadeite (Fig. 7)}

The $\log r-1 / T$ curve of alkali-feldspar cannot be fitted by straight lines. The behavior is very different from that of the normal semi-conductors. The $\log r-1 / T$ curve deviates from the straight line above $700^{\circ} \mathrm{C}$. 
Below $700^{\circ} \mathrm{C}$ the alkali-feldspar consists of two distinct phases, potassium-rich and sodiumrich phases. These phases are finely intermingled to form the perthite structure (see, e.g. Deer et al., 1963). The perthite structure, however, disappears above $700^{\circ} \mathrm{C}$ because potash feldspar and albite constitute a complete solid solution at such high temperatures. Therefore the inflection of the $\log r-1 / T$ curve of alkali-feldspar may be attributed to the change of $\sigma_{0}$ and activation energy associated with the disappearance of the perthite structure.

The inflection of the $\log r-1 / T$ curve of jadeite (Fig. 7) may be also due to the change of $\sigma_{0}$ and $\epsilon$ with temperature, though it is possible to attribute it to the transition of conduction mechanism. It is not possible to draw a definite conclusion on the cause of the inflection of the $\log r-1 / T$ curve of jadeite from the data available at present.

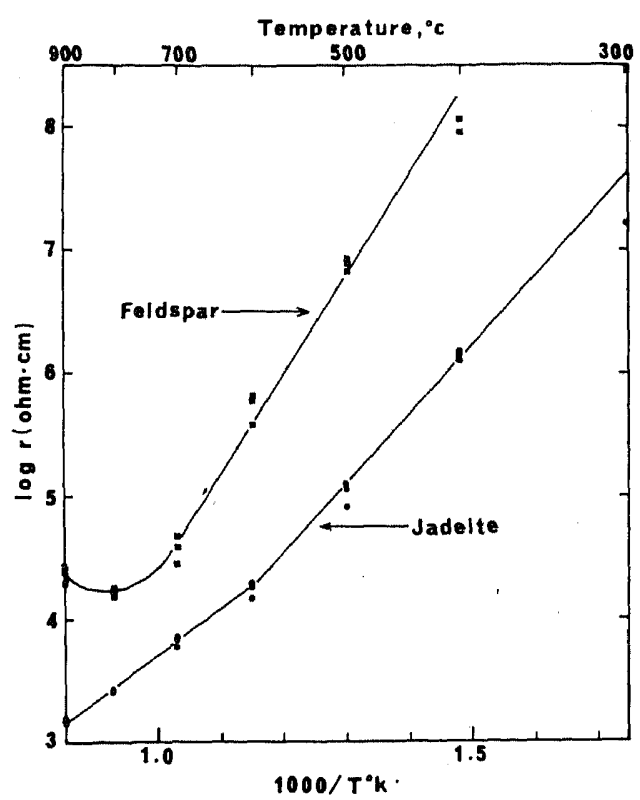

Fig. 7. Electrical conductivities of alkali-feldspar and jadeite.

\section{§. Conclusions}

Electrical conductivities of various rockforming minerals were measured over the temperature range 500 to $1200^{\circ} \mathrm{K}$. Although the type of conduction mechanism cannot be determined definitely, the activation energies of various rock-forming minerals fall between 0.7 and $1.7 \mathrm{eV}$ over the temperature range studied. The pre-exponential term $\sigma_{0}$, however, varies several orders of magnitude for various rock-forming minerals. Therefore the range of the absolute value of the electrical conductivity cannot be determined unless the chemical composition of the sample is known. To derive useful informations on the state of the earth's interior from the conductivity distribution, it is essential to study rockforming minerals with controlled chemical compositions. It is hoped to measure the electrical conductivity under a condition where the effects of various factors can be separated.

\section{Acknowledgments}

The authors are grateful to Dr. H. Fujisawa for valuable comments on this paper.

\section{References}

АкIмото, S. and H. FUJISAWA:

Demonstration of the electrical conductivity jump produced by the olivine-spinel transition, J. Geophys. Res., 70, 443-449, 1965.

BRADLEY, R. S., A. K. JAMIL and D. C. MUNRO: Electrical conductivity of olivine at high temperatures and pressures, Geochim. Cosmochim. Acta, 28, 1669-1678, 1964.

Clark, SYDNEY P. Jr.:

Absorption spectra of some silicates in the visible and near infrared, Am. Mineralogist, 42, 732-742, 1957.

Coster, H. P.:

The electrical conductivity of rocks at high temperatures, Monthly Notices Roy. Astron. Soc. Geophys. Suppl., 5, 193-199, 1948

DeER, W.A., R. A. HowIE and J. ZUSSMAN: Rock-Forming.Minerals, 4, John Wiley and Sons Inc., New York, 1963.

EXNER, P. M.:

Zur inneren Leitung von Quartz bei 100-150 und von Glas bei Zimmertemperatur, Verhandlungen der Deutschen Physikalischen Gesellschaft, 3, 26-30, 1901.

FUKAO, Y., H. MizUTANI and S. UYEDA:

Optical absorption spectra at high temperatures and radiative thermal conductivity of olivines, Physics of the Earth and Plandtary Interiors, 1, 57-62, 1967.

HAMILTON, R. M.: 
Temperature variation at constant pressures of the electrical conductivity of periclase and olivine, J. Geophys. Res., 70, 5679-5692, 1965.

Hughes, H.:

The pressure effect on the electrical conductivity of peridot, J. Geophys. Res., 60, 187-191, 1955.

KANAMORI, H., N. FUJII and H. MIZUTANI:

The measurement of thermal diffusivity of rock forming minerals over the temperature range from $300^{\circ} \mathrm{K}$ to $1100^{\circ} \mathrm{K}, J$. Geophys. Res., 73, 595-605 1968.

KITTEL, C.

Introduction to Solid State Physics, 2, p. 358, John Wiley and Sons Inc., New York, 1956.

LAWSON, A. W. and JOHN C. JAMIESON:

Energy transfer in the earth's mantle, $J$. Geol., 66, 540-551, 1958.

MCCARTHY, K. A., S. S. BALlaRD and W. L. WOLFE: Transmission and absorption of special crystals and certain glasses, in American Institute of Physics Handbook, 2, edited by Bruce H. Billings, V145-V178, McGrawHill Book Company Inc., New York, 1963.

MotT, N. F. and R. W. GuRney:

Electronic Processes in Ionic Crystals, 2nd ed., Dover Publication, New York, 1948.

NorITOMI, K. :

Studies on the change of electrical conductivity with temperature of a few silicate minerals, Science Reports Toholu Univ., Ser. 5, 6, 119-126, 1955.
NoRITOMI, K.:

Studies on the electrical conductivity of a few samples of granite and andesite, Science Reports Tohoku Univ., Ser. 5, 7, 201-207, 1956.

NORITOMI, K. :

The electrical conductivity of rock and the determination of the electrical conductivity of the earth's interior, Journal of the Mining College, Akita Univ., Ser. $A, 1$, 27-59, 1961.

RIKITAKE, T.:

Electrical conductivity and temperature in the earth, Bull. Earthquake Res. Inst., Tokyo Univ., 30, 13-24, 1952.

SeTo, K.:

Chemical composition of olivine in Miyakejima, J. Japanese Associ. Mineralogists, Petrologists and Economic Geologists, 1, 23-24, 1929.

SHANKLAND, T. J.:

Synthesis and optical properties of forsterite, Tech. Rep. No. HP-16, Gordon Mc Kay Laboratory, Harvard Univ., 1966.

SOSMAN, R. B.:

The Properties of Silica, American Chemical Society Monograph Series No. 37, Chemical Catalog Company Inc., New York, 1927.

TOZER, D. C.:

The electrical properties of the earth's interior, in Phys. Chem. Earth, 3, edited by L. H. Ahrens, pp. 414-436, Pergamon Press, London, 1959. 